Prepared for the U.S. Department of Energy

under Contract DE-AC05-76RL01830

\title{
A Brief Technical Critique of Ehlig- Economides and Economides 2010: "Sequestering Carbon Dioxide in a Closed Underground Volume"
}

\author{
JJ Dooley \\ CL Davidson
}

April 2010

\section{Pacific Northwest}

NATIONAL LABORATORY 



\title{
DISCLAIMER
}

This report was prepared as an account of work sponsored by an agency of the United States Government. Neither the United States Government nor any agency thereof, nor Battelle Memorial Institute, nor any of their employees, makes any warranty, express or implied, or assumes any legal liability or responsibility for the accuracy, completeness, or usefulness of any information, apparatus, product, or process disclosed, or represents that its use would not infringe privately owned rights. Reference herein to any specific commercial product, process, or service by trade name, trademark, manufacturer, or otherwise does not necessarily constitute or imply its endorsement, recommendation, or favoring by the United States Government or any agency thereof, or Battelle Memorial Institute. The views and opinions of authors expressed herein do not necessarily state or reflect those of the United States Government or any agency thereof.

\author{
PACIFIC NORTHWEST NATIONAL LABORATORY \\ operated by \\ BATTELLE \\ for the \\ UNITED STATES DEPARTMENT OF ENERGY \\ under Contract DE-AC05-76RL01830
}

Printed in the United States of America
Available to DOE and DOE contractors from the Office of Scientific and Technical Information,
P.O. Box 62, Oak Ridge, TN 37831-0062;
ph: (865) 576-8401
fax: $(865)$ 576-5728
email: reports@adonis.osti.gov

\begin{abstract}
Available to the public from the National Technical Information Service, U.S. Department of Commerce, 5285 Port Royal Rd., Springfield, VA 22161 ph: (800) 553-6847 fax: $(703) 605-6900$ email: orders@ntis.fedworld.gov online ordering: http://www.ntis.gov/ordering.htm
\end{abstract}

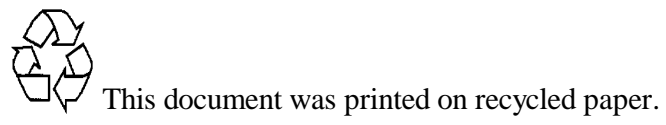


PNNL-19249

\begin{abstract}
In their 2010 paper, "Sequestering Carbon Dioxide in a Closed Underground Volume," authors Ehlig-Economides and Economides assert that "underground carbon dioxide sequestration via bulk $\mathrm{CO}_{2}$ injection is not feasible at any cost." The authors base this conclusion on a number of assumptions that the peer reviewed technical literature and decades of carbon dioxide $\left(\mathrm{CO}_{2}\right)$ injection experience have proven invalid. In particular, the paper is built upon two flawed premises: first, that effective $\mathrm{CO}_{2}$ storage requires the presence of complete structural closure bounded on all sides by impermeable media, and second, that any other storage system is guaranteed to leak. These two assumptions inform every aspect of the authors' analyses, and without them, the paper fails to prove its conclusions. The assertion put forward by Ehlig-Economides and Economides that anthropogenic $\mathrm{CO}_{2}$ cannot be stored in deep geologic formations is refuted by even the most cursory examination of the more than 25 years of accumulated commercial carbon dioxide capture and storage experience.
\end{abstract}

Key Words: carbon dioxide capture and storage; $\mathrm{CO}_{2}$ emissions mitigation; feasibility; structural traps; $\mathrm{CO}_{2}$ storage mechanisms; cost; security of storage; carbon sequestration; climate change; global warming. 
In their 2010 paper, "Sequestering Carbon Dioxide in a Closed Underground Volume," ${ }^{1}$ authors Ehlig-Economides and Economides assert that "underground carbon dioxide sequestration via bulk $\mathrm{CO}_{2}$ injection is not feasible at any cost." The authors base this conclusion on a number of assumptions that have been proven invalid by the peer reviewed technical literature and decades of carbon dioxide $\left(\mathrm{CO}_{2}\right)$ injection experience. In particular, the paper is built upon two key assumptions:

1.) Effective $\mathrm{CO}_{2}$ storage requires the presence of a hydrologically isolated, completely closed geologic structure; and

2.) Any other storage system is guaranteed to leak.

These two assumptions inform every aspect of the analysis presented by the paper, and without them, the authors' factually inaccurate conclusions are left unsupported by their analysis. Thus, it is critical to first address these two flawed premises.

\section{Safe, secure geologic $\mathrm{CO}_{2}$ storage does not require complete structural closure}

In the Ehlig-Economides and Economides article, a closed system is defined as a finite subsurface volume, structurally bounded on all sides by impermeable geologic media and that is fully or nearly saturated with formation fluids - some combination of oil, natural gas, and brine. Given that the geologic formation where the $\mathrm{CO}_{2}$ is to be stored and the associated formation fluids are largely incompressible, the assumption that the system is closed leads directly to the conclusion that the only volume available for $\mathrm{CO}_{2}$ storage is created by increasing the pressure in the system to a level below the fracture pressure of the caprock, resulting in a very small marginal potential storage volume. Under these assumptions, Ehlig-Economides and Economides argue that the deployment of carbon dioxide capture and storage (CCS) technologies at a large $\mathrm{CO}_{2}$ point source such as a base-load, coal-fired power plant would be extremely challenging because it would require an extraordinarily large storage field. The total number of suitable sites that would meet the highly arbitrary criteria set forth by the Ehlig-Economides and Economides paper while still satisfying the large capacity requirements to accommodate storage needs over a facility's 30-50 year lifetime would likely be extremely limited. Thus, based on these assumptions, the authors conclude that, "[CCS] is not a practical means to provide any substantive reduction in $\mathrm{CO}_{2}$ emissions, although it has been repeatedly presented as such by others."

\footnotetext{
${ }^{1}$ Ehlig-Economides, C. and M. J. Economides. "Sequestering Carbon Dioxide in a Closed Underground Volume." J. Petrol. Sci. Eng. 70(1-2):123-130. Virtually the same paper was published earlier in 2009 as M.J. Economides and C.A. Ehlig-Economides. 2009. "Sequestering Carbon Dioxide in a Closed Underground Volume." Society of Petroleum Engineers Annual Technical Conference and Exhibition, 4-7 October 2009, New Orleans, Louisiana. DOI: 10.2118/124430-MS.
}

The arbitrary assumptions employed by Ehlig-Economides and Economides essentially describe a subsurface vessel, with defined, impermeable boundaries on all sides, into which fluid is injected and total injection volume is limited by the properties of the vessel itself. Though it is not based on scientific criteria for safe, secure $\mathrm{CO}_{2}$ storage, this system definition drastically limits the total storage capacity and leads directly to the authors' pessimistic conclusions regarding the feasibility of large-scale use of CCS. 
Given the impact of the authors' assumptions on their analysis and final conclusions, it is important to understand whether these assumptions represent a typical or realistic base case for $\mathrm{CO}_{2}$ storage projects. Here, it is clear that they do not and instead represent a case so nonoptimal that it is difficult to imagine a $\mathrm{CO}_{2}$ source faced with this storage option to pursue it in the presence of other possibly less expensive mitigation options (e.g., transport to a more amenable site, fuel switching, purchasing $\mathrm{CO}_{2}$ offsets). Moreover, the case is not reflective of the majority of storage opportunities that could be encountered in the large, regional storage formations likely to serve as "baseload" storage capacity in the U.S. and elsewhere (Dahowski et al. 2010, Dooley et al. 2009, Wise et al. 2007, Dooley et al. 2006, Dahowski et al. 2005). Instead of describing a typical storage project similar to those being implemented at commercial and demonstration scales around the world, the assumptions employed by Ehlig-Economides and Economides essentially describe a subsurface vessel, with defined, impermeable boundaries on all sides, into which fluid is injected and where total injection volume is limited by the properties of the vessel itself. This combination of characteristics is geologically rare, as well as unnecessary and possibly counterproductive in terms of safely storing large quantities of anthropogenic $\mathrm{CO}_{2}$ in the deep subsurface.

The authors' assumptions regarding the pressure-limited injection volumes of closed structures severely constrains storage capacities, a finding which they invoke to support their pessimistic views of the viability of CCS. Methods for calculating $\mathrm{CO}_{2}$ storage capacity have been under development for well over a decade (e.g., Holloway et al. 1996), and approaches like the one employed by Ehlig-Economides and Economides have been rejected in favor of methodologies that reflect more realistic assumptions, based in part upon knowledge gained from ongoing $\mathrm{CO}_{2}$ storage projects. Instead of pressure-limited storage capacity estimation, current state-of-the-art capacity methodologies take a storage efficiency approach, representing the amount of $\mathrm{CO}_{2}$ that can be stored in a given volume of pore space. Many current assessments of geologic $\mathrm{CO}_{2}$ storage capacity employ tight constraints on storage space availability as a sensitivity analysis (e.g., NETL 2007, Dahowski et al. 2005, Dahowski et al. 2009, Edmonds et al. 2007) but these analyses are used to inform a discussion of the theoretical versus technically achievable storage capacity, not to account for the exclusive use of closed trapping systems, and by no means do the authors of these studies express this as a binding constraint, as asserted in the Ehlig-Economides and Economides paper.

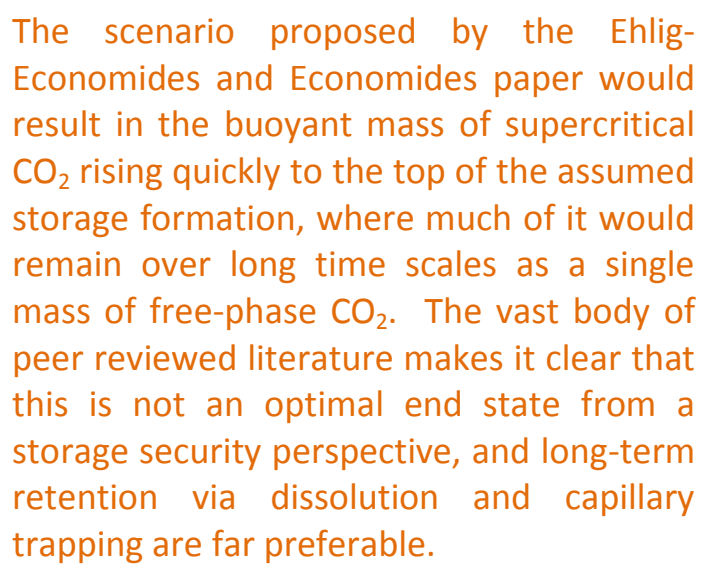

Capacity estimation methodology aside, the subsurface contains very few closed vessel-like structures of the volumes that would be of interest for $\mathrm{CO}_{2}$ storage. Also, in the vast majority of cases, fluid in the deep subsurface - whether oil, natural gas, or brackish formation waters - is driven by pressure and density differences both laterally and vertically along preferential paths dictated by relative permeability (Bryant et al. 2006). This fluid flow within the storage formation can increase the security of long-term $\mathrm{CO}_{2}$ storage. Research documented in the peer reviewed literature has demonstrated the value of $\mathrm{CO}_{2}$ storage in large, regionally extensive 
reservoirs (Bachu 2003, Burton et al. 2008). In particular, engineering $\mathrm{CO}_{2}$ injection to promote the mobility of $\mathrm{CO}_{2}$ through the brine-saturated rock of the storage zone has been shown to result in more secure $\mathrm{CO}_{2}$ storage via secondary trapping mechanisms such as capillary and dissolution trapping (IPCC 2005, Benson 2008, Hovorka et al. 2006). These trapping processes result in storage that is significantly more secure than the buoyancy-driven hydrodynamic trapping process that dominates the early years of any $\mathrm{CO}_{2}$ storage project. But without fluid flow to mix the $\mathrm{CO}_{2}$ with formation waters, storage under the scenario proposed by EhligEconomides and Economides would rely on hydrodynamic trapping for a far longer period. Under their scenario, the buoyant mass of supercritical $\mathrm{CO}_{2}$ would rise quickly to the top of the storage formation, where much of it would remain over long time scales as free-phase $\mathrm{CO}_{2}$. Dissolution processes would still occur, but lacking fluid flow in the formation, this process would take significantly more time than it would otherwise. Increasing the amount of pore space and formation fluid that the injected $\mathrm{CO}_{2}$ comes in contact with helps to speed the transition from pure hydrodynamic trapping to these longer-term, and higher security mechanisms. Both capillary and dissolution trapping mechanisms lessen the chance of $\mathrm{CO}_{2}$ moving out of the storage formation due to immobilization of trapped $\mathrm{CO}_{2}$ and a reversal of the buoyancy effect ${ }^{2}$, respectively. This represents a far more secure end state from a storage perspective, and more desirable than hydrodynamic trapping of the free-phase $\mathrm{CO}_{2}$ plume against the caprock for longer time frames. Considering that vertically and laterally extensive storage formations provide for greater contact between the stored $\mathrm{CO}_{2}$ and the target storage reservoir, and that this leads to increased storage security over time, it is difficult to see why the Ehlig-Economides and Economides analysis is based exclusively on a closed system.

However, even if complete structural closure was required to store $\mathrm{CO}_{2}$ in the subsurface, the assertion by Ehlig-Economides and Economides that total storage volumes would be so small as to negate the value of doing CCS is misinformed. While we have not specifically examined the arbitrarily over-constrained case put forward by Ehlig-Economides and Economides, we have published research demonstrating that, if only a relatively small fraction of the estimated $\mathrm{CO}_{2}$ storage resource is actually achievable, the value of having CCS in society's portfolio of responses to climate change is still on the order of trillions of dollars (Edmonds et al., 2007). Thus, even if the actual realizable $\mathrm{CO}_{2}$ storage potentials are orders of magnitude smaller than currently estimated, the relative cost of employing CCS as a means of addressing climate change could still be competitive with other large scale emissions mitigation measures. The assertion that " $\mathrm{CO}_{2}$ storage is infeasible at any cost," is pure hyperbole.

\section{Structural closure does not equate to the highest storage security}

The assertion that $\mathrm{CO}_{2}$ storage in open formations must inevitably lead to the release of $\mathrm{CO}_{2}$ back to the atmosphere thus negating the effectiveness of geologic $\mathrm{CO}_{2}$ storage as a means of addressing climate change is contradicted by an overwhelming volume of technical literature. Ehlig-Economides and Economides state that open formations would be unacceptable for geologic $\mathrm{CO}_{2}$ storage because:

\footnotetext{
${ }^{2}$ While free-phase supercritical $\mathrm{CO}_{2}$ is less dense than water, rising to the top of the formation under buoyancy, brine becomes more dense as $\mathrm{CO}_{2}$ is dissolved, with density of the aqueous phase increasing as a function of $\mathrm{CO}_{2}$ saturation. Thus, the most highly $\mathrm{CO}_{2}$-saturated water sinks to the bottom of the reservoir, with brine with less (or no) dissolved $\mathrm{CO}_{2}$ driven up by buoyancy (Garcia 2001).
} 


\begin{abstract}
The open aquifer ... must either outcrop to the land surface or in a stream, lake, or ocean bed where it would be in equilibrium either with atmospheric pressure or with the pressure at the stream, lake or ocean bottom. An outcropping aquifer would provide a potential path for injected $\mathrm{CO}_{2}$ to escape back to the atmosphere, thereby defeating the purpose of $\mathrm{CO}_{2}$ sequestration.
\end{abstract}

While injected supercritical $\mathrm{CO}_{2}$ is buoyant within the storage formation at the time of injection and therefore reliant on structural and stratigraphic trapping as the primary retention mechanism, over time other processes - in particular solubility and capillary / residual gas trapping - become the dominant mechanisms keeping $\mathrm{CO}_{2}$ in the storage formation (see Figure 1). These processes slow and eventually immobilize the $\mathrm{CO}_{2}$ in the formation, reversing the density-driven flow to allow $\mathrm{CO}_{2}$-saturated water to sink in the formation and decreasing the mechanisms behind buoyancy-driven leakage issues that must be considered early in the storage process (Benson 2008, Hovorka et al., 2006). This allows for the definition of a finite boundary on the extent of $\mathrm{CO}_{2}$ migration during storage, contradicting the implication that injected $\mathrm{CO}_{2}$ will simply migrate forever until it finds an outflow zone or other migration pathway out of the storage formation.

The Ehlig-Economides and Economides paper categorically dismisses the technical literature that has shown benefits associated with these secondary and tertiary trapping mechanisms for injected $\mathrm{CO}_{2}$ because they involve "woefully slow process[es]." While buoyancy trapping tends to represent the bulk of $\mathrm{CO}_{2}$ trapped in the near-term, the literature is clear that capillary, solubility and mineral trapping represent a higher degree of long-term security and stability of the stored $\mathrm{CO}_{2}$. While sites must be characterized to ensure their suitability for buoyancy-driven trapping in the near-term, ultimately these secondary and tertiary processes will render the $\mathrm{CO}_{2}$ immobile within the formation, preventing it from reaching distant migration pathways to the surface.

In response to the authors' implication that $\mathrm{CO}_{2}$ loss at hydrologic outflow boundaries is inevitable, it is important to note that preinjection site selection and characterization efforts are designed to identify these sorts of risks and ensure that the engineered system will not result in loss of $\mathrm{CO}_{2}$ by migration from outflow boundaries or any other leakage pathway. Further, it is clear from the proposed EPA rulemaking on the governance of $\mathrm{CO}_{2}$ injection into the subsurface (Federal Register 2008) that a project with a known leakage pathway for $\mathrm{CO}_{2}$ that could not be adequately mitigated (e.g., by plugging an abandoned well penetrating the storage zone) would not be granted an injection permit. Thus, the sites that are selected and permitted for $\mathrm{CO}_{2}$ storage are assured to be an adequate distance from outflow zones and are managed to prevent the migration

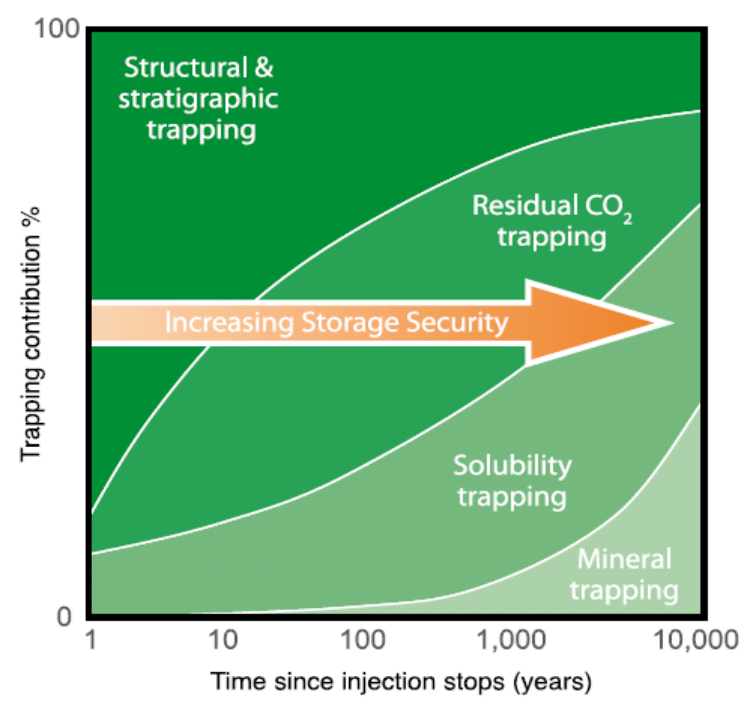

Figure 1. Both physical and chemical trapping mechanisms play important roles over the lifetime of a $\mathrm{CO}_{2}$ storage project (from Benson 2008). 
For scale, the timeframes required for solubility trapping via dissolution of the injected $\mathrm{CO}_{2}$ are typically on the order of hundreds to thousands of years, not tens of thousands or millions of years (IPCC 2005 and Benson 2008). It is important to note that these are likely conservative estimates, and that the higher the flow gradient in the formation, the faster these processes take place. Modeling employed as a part of site characterization and project management is able to provide a more realistic estimate of this timeframe as a function of parameters specific to the reservoir being evaluated for storage. Coupled with a detailed understanding of the storage formation itself and the broader regional geology, projects can be selected and managed to ensure that injected $\mathrm{CO}_{2}$ never reaches hydrologic outflow zones.

\section{On the Economides' Conclusions}

The conclusions asserted by the Ehlig-Economides and Economides paper are flawed and stand in stark contrast to the enormous body of literature and field experience on $\mathrm{CO}_{2}$ injection and storage in the subsurface. The policy and regulatory communities must not rely on unsupported conclusions such as "underground carbon dioxide sequestration via bulk $\mathrm{CO}_{2}$ injection is not feasible at any cost" and that "geologic sequestration of $\mathrm{CO}_{2}$ [is] a profoundly non-feasible option for the management of $\mathrm{CO}_{2}$ emissions" because they are not based on good science or thoughtful analysis.

The technical feasibility of storing $\mathrm{CO}_{2}$ in deep geologic formations is entirely proven by the existence of the Statoil Sleipner project, which has been injecting approximately $1 \mathrm{MtCO}_{2} /$ year into a deep geologic formation below the North Sea for nearly a decade and a half. The fate of the $\mathrm{CO}_{2}$ injected at Sleipner has been monitored via an extensive and scientifically rigorous measurement, monitoring and verification (MMV) program. This MMV process continues to verify that $\mathrm{CO}_{2}$ injected into the storage formation remains isolated in the subsurface where it cannot contribute to anthropogenic climate change. The more than 25 years of cumulative experience and the significant scientific and technological knowledge gained from Sleipner and the other three large commercial end-to-end commercial CCS projects - Snøhvit, In Salah and Weyburn - are further proof that "underground carbon dioxide sequestration via bulk $\mathrm{CO}_{2}$ injection" is feasible and that the cost of doing so must not be infinite as asserted by EhligEconomides and Economides. ${ }^{3}$

The assertion that subsurface storage of large volumes of fluids is impossible is also inconsistent with the experience gained from $\mathrm{CO}_{2}$ injection pilot projects around the world and countless other fluid injection projects over the last several decades such as the injection of hundreds billions of gallons of waste fluid into the subsurface under the auspices of the U.S. EPA Underground Injection Control Program (EPA, 2002). Not only are these projects technically and economically viable, they are effectively managed, and safely regulated.

The CCS policy and regulatory communities are in need of robust, well-founded science and engineering upon which to base their decisions regarding how to govern geologic $\mathrm{CO}_{2}$ storage. Innovative ideas that challenge the conventional wisdom on issues critical to the success of commercial-scale $\mathrm{CO}_{2}$ storage are and will continue to be welcomed by the technical

\footnotetext{
${ }^{3}$ Dooley et al. (2009) provide an overview of the $\mathrm{CO}_{2}$ capture, storage and measurement, monitoring and verification technologies that have been successfully employed at Sleipner, Snøhvit, In Salah and Weyburn.
} 
PNNL-19249

community. While the Ehlig-Economides and Economides paper does highlight the need for continued research and field work to better understand how CCS will deploy in the real world, unfounded conclusions such as "underground carbon dioxide sequestration via bulk $\mathrm{CO}_{2}$ injection is not feasible at any cost" and "geologic sequestration of $\mathrm{CO}_{2}$ [is] a profoundly nonfeasible option for the management of $\mathrm{CO}_{2}$ emissions" do not withstand scientific scrutiny. Unsupported opinions and hyperbole do not represent a constructive contribution to the ongoing technical, policy, or regulatory dialogues related to the potential benefits and challenges associated with CCS. 
PNNL-19249

\section{References:}

Bachu S. 2003. "Screening and ranking of sedimentary basins for sequestration of $\mathrm{CO}_{2}$ in geological media in response to climate change." Environmental Geology (2003) 44:277-289. DOI 10.1007/s00254003-0762-9.

Benson SM, 2008. Multi-Phase Flow and Trapping of $\mathrm{CO}_{2}$ in Saline Aquifers. (Paper No. OTC 19244). Published in the Proceedings of 2008 Offshore Technology Conference held in Houston, TX, USA, May 5-8, 2008.

Bryant SL, S Lakshminarasimhan and GA Pope. "Buoyancy Dominated Multiphase Flow and Its Impact on Geological Seqeustration of $\mathrm{CO}_{2}$." Paper SPE 99938, presented at The Society of Petroleum Engineers $16^{\text {th }}$ Symposium on Improved Oil Recovery. Tulsa, Oklahoma. 22-26 April 2006.

Dahowski RT, X Li, CL Davidson, N Wei, and JJ Dooley. 2010. Regional Opportunities for Carbon Dioxide Capture and Storage in China: A Comprehensive $\mathrm{CO}_{2}$ Storage Cost Curve and Analysis of the Potential for Large Scale Carbon Dioxide Capture and Storage in the People's Republic of China . PNNL-19091, Pacific Northwest National Laboratory, Richland, WA.

Dahowski RT, JJ Dooley, CL Davidson, S Bachu and N Gupta. 2005. Building the Cost Curves for $\mathrm{CO}_{2}$ Storage: North America. Technical Report 2005/3. International Energy Agency Greenhouse Gas R\&D Programme.

Dooley JJ, CL Davidson and RT Dahowski. 2009. "An Assessment of the Commercial Availability of Carbon Dioxide Capture and Storage Technologies as of June 2009." Joint Global Change Research Institute. Pacific Northwest National Laboratory. June 2009. PNNL-18520.

Dooley, JJ, CL Davidson, RT Dahowski, MA Wise, N Gupta, SH Kim, and EL Malone. 2006. "Carbon Dioxide Capture and Geologic Storage: A Key Component of a Global Energy Technology Strategy to Address Climate Change." Joint Global Change Research Institute, Battelle Pacific Northwest Division. May 2006. PNWD-3602. College Park, MD.

Edmonds JA, JJ Dooley, S Kim, S Friedman, and MA Wise. Technology in an Integrated Assessment Model: The Potential Regional Deployment of Carbon Capture and Storage in the Context of Global $\mathrm{CO}_{2}$ Stabilization. (In) Human-induced Climate Change: An Interdisciplinary Assessment, ed. Michael Schlesinger, Haroon Kheshgi, Joel Smith, Francisco de la Chesnaye, John M. Reilly, Tom Wilson and Charles Kolstad. Published by Cambridge University Press. Cambridge University Press 2007. pp. 181197.

Environmental Protection Agency. 2002. "Protecting Drinking Water through Underground Injection Control: Drinking Water Pocket Guide \#2." http://www.epa.gov/safewater/uic/pdfs/pocketguide_uic_protectng_dw_thru_uic.pdf

Federal Register, 2008. 40 CFR Parts 144 and 146 Federal Requirements Under the Underground Injection Control (UIC) Program for Carbon Dioxide $\left(\mathrm{CO}_{2}\right)$ Geologic Sequestration (GS) Wells. Proposed Rule, Friday, July 25, 2008; Federal Register 73, 144, 43492-43541.

Garcia JE. 2001. Density of aqueous solutions of $\mathrm{CO}_{2}$. Lawrence Berkeley National Laboratory: Lawrence Berkeley National Laboratory. LBNL Paper LBNL-49023. Retrieved from: http://escholarship.org/uc/item/6dn022hb 
PNNL-19249

Gupta N and ES Bair. 1997. "Variable-density flow in the midcontinent basins and arches region of the United States." Water Resources Research, vol. 33, no. 8, pp. 1785-1802.

Holloway S, JP Heedrick, LGH van der Meer, I Czerichowski-Lauriol, R Harrison, E Linderberg, JR Summerfield, C Rochelle, T Schwartzkopf, O Karrstad, B Berger. The underground disposal of $\mathrm{CO}_{2}$. EU Joule II Programme summary report. British Geological Survey, Keysworth, UK; 1996.

Hovorka SD, SM Benson, C Doughty, BM Freifeld, S Sakurai, TM Daley, YK Kharaka, MH Holtz, RC Trautz, H Seay Nance, LR Myer, KG Knauss, 2006. Measuring permanence of $\mathrm{CO}_{2}$ storage in saline formations: the Frio experiment. Environ. Geosci. 13 (June (2)), 105-121, doi:10.1306/eg.11210505011.

Intergovernmental Panel on Climate Change. (IPCC 2005). Special Report on Carbon Dioxide Capture and Storage. IPCC, 2005 - Bert Metz, Ogunlade Davidson, Heleen de Coninck, Manuela Loos and Leo Meyer (Eds.). Cambridge University Press, UK. pp 431.

Wise MA, JJ Dooley, RT Dahowski, and CL Davidson (2007). "Modeling the impacts of climate policy on the deployment of carbon dioxide capture and geologic storage across electric power regions in the United States." International Journal of Greenhouse Gas Control. Volume 1, Issue 2, April 2007, Pages 261-270. doi:10.1016/S1750-5836(07)00017-5 